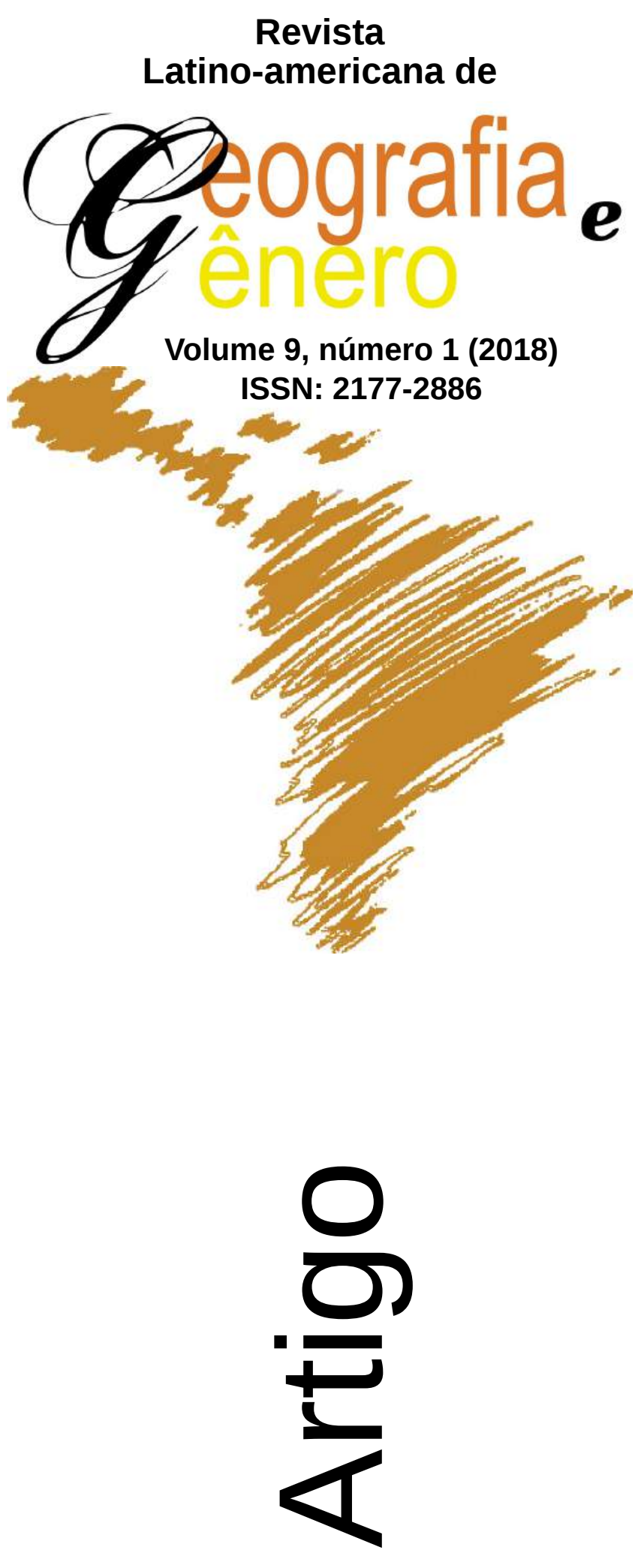

Práticas de Cura pelas Mãos de Dona Lenil, Sabedora da Comunidade Enseada do Aritapera, Várzea de Santarém, Pará

Prácticas de Sanación por las Manos de Doña Lenil, Sabedora de la Comunidad Enseada del Aritapera, Várzea de Santarém, Pará

Cure Practices by the Hands of Lady Lenil, Sage Woman of the Community of Aritapera Cove, Várzea de Santarém, Pará
Ádria Fabíola Pinheiro de Sousa Universidade Federal de Rondônia - Brasil fabyolasousa@gmail.com
Josué da Costa Silva
Universidade Federal de Rondônia - Brasill jcosta1709@gmail.com

Como citar este artigo:

SOUSA, Ádria Fabíola Pinheiro; SILVA, Josué da Costa. Práticas de Cura pelas Mãos de Dona Lenil, Sabedora da Comunidade Enseada do Aritapera, Várzea de Santarém, Pará. Revista Latino Americana de Geografia e Gênero, v. 9, n. 1, p. 120-137, 2018. ISSN 2177-2886.

Disponível em:

http://www.revistas2.uepg.br/index.php/rlagg 


\title{
Práticas de Cura pelas Mãos de Dona Lenil, Sabedora da Comunidade Enseada do Aritapera, Várzea de Santarém, Pará
}

\author{
Prácticas de Sanación por las Manos de Doña Lenil, Sabedora de la \\ Comunidad Enseada del Aritapera, Várzea de Santarém, Pará
}

\section{Cure Practices by the Hands of Lady Lenil, Sage Woman of the Community of Aritapera Cove, Várzea de Santarém, Pará}

\section{Resumo}

Este artigo busca fazer um estudo do modo de vida do lugar, por meio da análise dos processos de constituição da história de vida de Dona Lenil, colaboradora desta pesquisa, pautado nas relações de cura caracterizada como uma manifestação de encantaria tradicionalmente estabelecida na comunidade Enseada do Aritapera. Caracteriza-se como uma pesquisa qualitativa e utiliza como método a fenomenologia. Como metodologia utilizamos a pesquisa de campo e a pesquisa participante. Assim fizemos o registro da história de vida de Dona Lenil na qual pudemos observar a relação do lugar com essas práticas e suas interrelações com os ritos e mitos que se estabelecem na comunidade como marcadores culturais que afirmam a identidade do lugar ribeirinho.

Palavras-Chave: Historia de Vida; Cura; Saberes; Marcadores Culturais; Encantaria.

\section{Resumen}

Este artículo pretende hacer un estudio del modo de vida del lugar, a través del análisis de los procesos de constitución de la historia de vida de Doña Lenil, colaboradora de esta investigación, pautado en las relaciones de sanación caracterizada como una manifestación de encanteríos tradicionalmente establecidos en la comunidad Enseada del Aritapera. Se caracteriza como una investigación cualitativa y utiliza como método la fenomenología. Como metodología utilizamos la investigación de campo y la investigación participante. Así hicimos el registro de la historia de vida de Doña Lenil en la que pudimos observar la relación del lugar con esas prácticas y sus interrelaciones con los ritos y mitos que se establecen en la comunidad como marcadores culturales que afirman la identidad del lugar ribereño.

Palabras-Clave: Historia de Vida; Sanación; Saberes; Marcadores Culturales; Encanterío.

\begin{abstract}
This paper is a study about the way of life of a place, by means of an analysis of the life story of Lady Lenil, a sage woman who was a collaborator of this research. The article is guided by the conception of cure relations as a manifestation of the encantaria traditionally practiced in the community of Aritapera Cove. It is characterized as a qualitative research and resorts to the phenomenology method. As for methodology, we performed a field research and a participant research to make the record of Lady Lenil's life story, in which we could observe the relations between the place and these practices and their interrelations with the rites and myths established as cultural markers of the community, which in turn affirm the identity of this riverine settlement.
\end{abstract}

Keywords: History of Life; Cure; Knowledge; Encantaria; Cultural Markers.

Ádria Fabíola Pinheiro de Sousa, Josué Costa da Silva 


\section{Introdução}

Tendo como referência o relato oral e memória, este artigo busca fazer um estudo do modo de vida do lugar e analisar os processos de constituição da história de vida de Dona Lenil, colaboradora desta pesquisa, pautado nas relações de cura, tradicionalmente estabelecidas na comunidade Enseada do Aritapera.

A intenção de adentrar nesta discussão no campo da geografia é de contribuir para o debate dos valores que o ser humano atribui às suas experiências de vida articuladas à organização espacial que adotam em torno de um lugar envolto de significações simbólicas, considerando que este tema é bastante comum aos olhares de outras ciências, mas ainda pouco trabalhado no campo da ciência geográfica.

Visa ainda à contribuição da ciência geográfica para a compreensão dos elos afetivos entre a pessoa e o lugar, voltando-se para o espaço do cotidiano, do vivido, do percebido. Além disso, pretende-se ampliar o espaço de debate sobre o tema, promovendo diálogos acadêmicos.

Logo, neste artigo, procuramos entender os processos de cura tradicionalmente estabelecidos em Aritapera, como (rezas, 'benzeção', 'puxação') por meio da história de vida de Dona Lenil, como elementos que integram a configuração das ocorrências de doenças como quebranto, mauolhado e outras doenças tidas como naturais - o conceito será apresentado adiante -, mas que necessitam da intermediação das práticas tradicionais de cura, também conhecidas como medicina tradicional, comumente utilizada pelos ribeirinhos da Amazônia. Estas práticas fazem parte do universo imaginário dos moradores de Aritapera e representam o plano do vivido, compreendidas como parte de sua trajetória de vida.

Temos como objetivo geral analisar de que forma as práticas de cura participam dos acontecimentos que marcam a experiência de vida dos moradores da comunidade Enseada do Aritapera, aqui, em especial, a de Dona Lenil, e dão sentido tanto à organização de suas histórias pessoais quanto ao lugar. Como objetivos específicos, procuramos entender: De que forma esse fenômeno cultural influencia na vida dos moradores da comunidade Enseada do Aritapera? Como ele se expressa no espaço geográfico? Como as relações com as práticas tradicionais de cura contribuem para a construção de uma identidade própria da mulher da várzea na Amazônia?

Este artigo busca realizar uma análise do fenômeno investigado, tendo como base as práticas de cura tradicionalmente estabelecidas na comunidade Enseada do Aritapera que fazem parte do universo cultural do lugar e tem como foco o relato oral da história de vida e memória de Dona Lenil, pautado nas práticas tradicionais de cura que são identificadas em Enseada, uma das comunidades da região do Aritapera.

Caracteriza-se como uma pesquisa qualitativa e utiliza-se como método a fenomenologia, a qual procura valorizar a percepção do indivíduo por meio de suas experiências vividas, ou seja, a relação do homem com o meio em que está inserido. Como metodologia utilizamos a pesquisa de campo onde, por meio da história oral, com a utilização de um gravador - que auxilia o registro da entrevista - fizemos o registro da história de vida de Dona Lenil. Também

Ádria Fabíola Pinheiro de Sousa, Josué Costa da Silva 
compõe a metodologia a pesquisa participante, uma vez que presenciamos, vivemos o lugar e estivemos próximos a nossa colaboradora durante sete dias. Dessa forma, para este artigo, conseguimos destacar as práticas tradicionais de cura por ela exercidas na comunidade Enseada do Aritapera onde pudemos observar a relação do lugar com essas práticas e suas inter-relações com os ritos e mitos que se estabelecem na comunidade como marcadores culturais que afirmam a identidade do lugar ribeirinho.

\section{Conhecendo o Lugar}

Aritapera é uma região situada na várzea do município de Santarém, estado do Pará, às margens do Rio Amazonas, caracteristicamente composta por igarapés, lagos, restingas e rios, marcada pelas cheias e pelas estiagens, sendo essas passagens distribuídas em períodos de semelhante duração ao longo do ano. Podemos considerar o rio como o recurso mais precioso para os ribeirinhos, não só de Aritapera, mas de toda a Amazônia.

Situado diante de uma natureza magnífica, de proporções monumentais, o caboclo, além de criar e desenvolver processos altamente criativos e eficazes de relação com ela, construiu um sistema cultural singular. Uma cultura viva, em evolução, integrada e formadora de identidade. Cultura que no sentido ético-estético, constitui uma espécie de paideia de bildung amazônica ${ }^{1}$, constituída por indivíduos formados segundo um modo de relação profunda com a natureza e dos homens entre si (LOUREIRO, 1995, p. 409).

A relação que percebemos do ser humano-ribeirinho/aritaperense para com o rio e com a natureza é de respeito e equilíbrio. Isso se torna ainda mais perceptível na época da estiagem, quando as águas barrentas do Amazonas inundam toda a vegetação, muitas vezes destruindo as suas plantações e tantas vezes não deixando nenhum pedaço de terra para se pisar, dessa forma entendemos que "os moradores aceitam pacificamente o rio levar todos os anos parte de suas terras, pois está levando o que é dele" (NASCIMENTO SILVA, 2000 p.36).

Figura 1 - Rio Amazonas, Enseada do Aritapera.

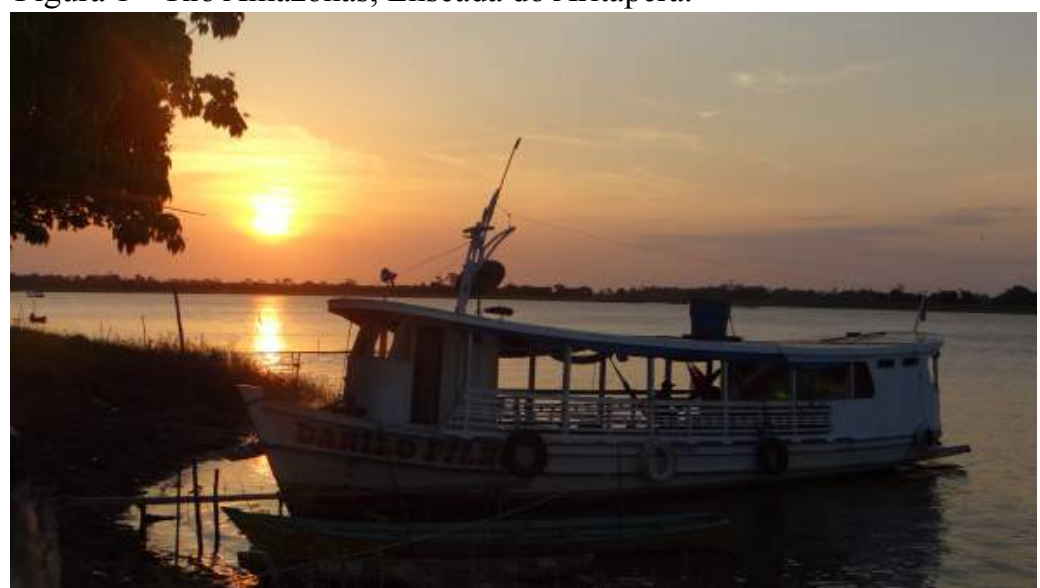

Fonte: SOUSA, Á. F.P. Rio Amazonas, comunidade Enseada do Aritapera/Santarém-PA, outubro de 2015.

Ádria Fabíola Pinheiro de Sousa, Josué Costa da Silva 
A Enseada do Aritapera, na maioria das vezes, denominada pelos moradores, apenas como "Enseada", fica à margem esquerda do rio Amazonas e durante o curso da viagem para a região do Aritapera, é a primeira comunidade a ser avistada.

Enseada do Aritapera, assim como as demais comunidades da região, é um lugar que contém vários paladares (gosto de peixe fresco, gosto de castanha sapucaia $^{2}$ ajuntada do pé, gosto do leite de vaca quentinho, tirado na hora); de muitos aromas (cheiro de água fresca que o vento traz na brisa da beira do rio, cheiro de mato molhado, cheiro de flores e frutos).

O tato está no contato direto com o rio, em pisar com os pés descalços na grama molhada, no assoalho ${ }^{3}$ frio, em andar nas bajaras ${ }^{4}$ sentindo o vento fresco passar pelo rosto e por entre os dedos e na sensação de poder pegá-lo. $\mathrm{O}$ ver é o conjunto de todos os sentidos. Mais importante é poder ver a alegria da convivência das pessoas em poder habitar em um lugar tão tranquilo e aconchegante.

Uma pessoa pode conhecer um lugar tanto de modo íntimo como conceitual. Pode articular ideias, mas ter dificuldades de expressar o que conhece pelos sentidos do tato, paladar, olfato, audição e até pela visão (TUAN, 2013, p. 15).

É por meio dos sentidos, como apresenta Tuan, que buscamos compreender, interpretar e experimentar o lugar que é Aritapera.

Figura 2 - Procissão de Santo Antônio.

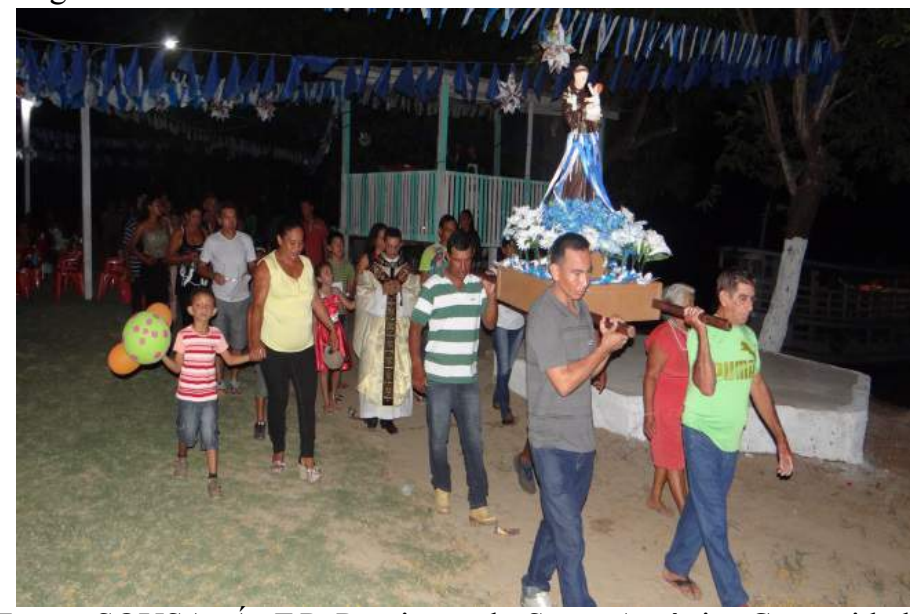

Fonte: SOUSA, Á. F.P. Procissão de Santo Antônio. Comunidade

Enseada do Aritapera/ Santarém-PA, outubro de 2015.

1 Tipo de formação social da Amazônia.

2 Lecythis pisonis Cambess, conhecida como castanha de sapucaia, é uma espécie cuja madeira apresenta diversos usos, além das cascas, folhas e sementes serem medicinais. As castanhas constituem excelente alimento, comparável a outras amêndoas conhecidas (Revista de Ciências Agroambientais, Alta Floresta, v.5, n.1, p.111 - 116, 2007). Disponível em: http://www.unemat.br/revistas/rcaa/docs/vol5/11_artigo_v5.pdf.

3 Tipo de piso feito de tábuas. As casas de Aritapera apresentam esse tipo de assoalho com elevação porque são casas palafitas (suspensas por grandes estacas de madeira).

4 Pequena embarcação feita de madeira. Costuma ser diferenciada da canoa por ter um tamanho maior, comportando mais pessoas.

Ádria Fabíola Pinheiro de Sousa, Josué Costa da Silva 


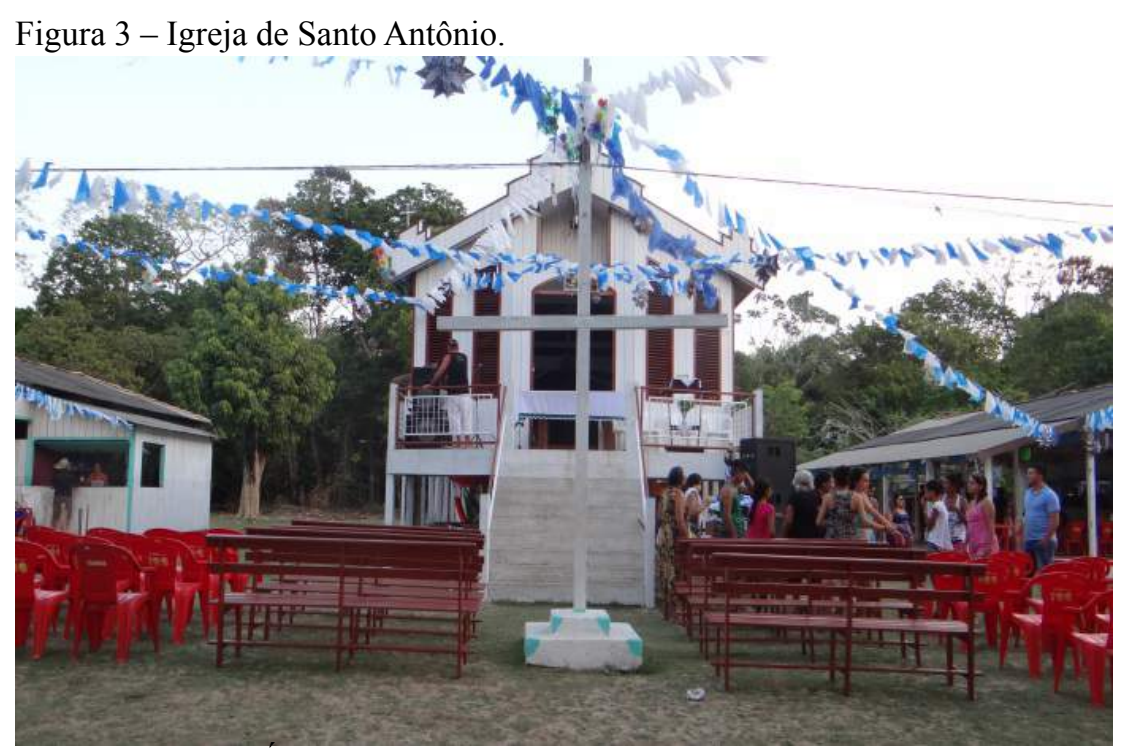

Fonte: SOUSA, A. F.P. Igreja de Santo Antônio. Comunidade Enseada do Aritapera/ Santarém-PA, outubro de 2015.

As imagens acima representam o espaço simbólico religioso da Enseada do Aritapera que concebe bem as relações de sociabilidade para os moradores do lugar. Movidos pela crença em seu santo padroeiro, os comunitários devotos se organizam em torno de sua festa em uma expressão de fé.

Tanto homens quanto mulheres dedicam trabalho voluntário ao padroeiro, intensificado na época da festividade, embora seja exercido durante todo o ano. Para a preparação da alimentação da festividade as mulheres se dividem no trabalho da cozinha com os doces, frituras de salgados e na preparação das refeições. Para os homens é reservado o serviço de bar e a montagem de barracas.

A festa religiosa é conjugada com a festa dançante, denominada de arraial, principal responsável pela arrecadação de fundos que subsidiem as despesas da festa e na arrecadação de algum dinheiro para a igreja. A festa não deixa de ser um atrativo principal das comemorações dos santos.

Dona Lenil é devota do santo e também participa da organização dos festejos, principalmente no que diz respeito à organização das missas e procissões.

\section{Dona Lenil, uma Sabedora da Comunidade Enseada do Aritapera}

Dona Lenil é uma senhora de 82 anos, moradora da comunidade Enseada do Aritapera, não tem filhos, há pouco tempo ficou viúva e por isso, atualmente, mora sozinha, mas a poucos metros de distância de seu sobrinho e de sua irmã. Dona Lenil é artesã de cuias bordadas 5 , costura desde a sua mocidade, é também poetiza, costuma revelar sua arte de escritora nos eventos da igreja de sua comunidade - Santo Antônio - e nos eventos da escola de sua comunidade.

5 Artesanato produzido pela Associação das Artesãs Ribeirinhas de Santarém - Asarisan. Chama-se cuia bordada, pela técnica aplicada na cuia preta que são rascunhos (desenhos iconográficos) florais e grafismos indígenas que decoram e dão vida e formato à peça artesanal. Dona Lenil é a artesã mais antiga da associação.

Ádria Fabíola Pinheiro de Sousa, Josué Costa da Silva 
Desde muito tempo Dona Lenil trabalha com práticas tradicionais de cura: benze, puxa, reza para mau-olhado, quebranto, espinha de peixe na garganta e acidentes específicos. Na comunidade ela é denominada como "a pessoa que entende" por saber tratar dessas doenças, por isso, podemos caracterizar a nossa colaboradora como uma sabedora e produtora de práticas de cura do lugar, considerando que estas práticas também são marcadores culturais do modo de vida ribeirinho, varjeiro ${ }^{6}$ ou beradeiro ${ }^{7}$.

A cultura do mundo rural de predominância ribeirinha constitui-se na expressão aceita como a mais representativa da cultura amazônica, seja quanto aos seus traços de originalidade, seja como produto da acumulação de experiências sociais e da criatividade dos seus habitantes. Aquela onde podem ser percebidas, mais fortemente, as raízes indígenas e caboclas tipificadoras de sua originalidade, florescentes ainda em nossos dias (LOUREIRO, 1995, p.55).

Dona Lenil diz que adquiriu esse saber local com a sua própria experiência de vida:

As coisas acontecem por acaso, a gente faz e se dá bem. Isso é um dom que a gente recebe. Deus não espalhou vários dons pra gente? E tudo aquilo que faz deve fazer com amor. Eu nunca cobrei de ninguém. Vendo as coisas que se passavam na minha frente, ai eu vou e faço. Vendo a necessidade dos outros a gente tem que ajudar e fazer sem medo (Lenil Silva, Enseada do Aritapera, 12.10.2015).

As práticas populares de cura identificadas na história de vida de Dona Lenil podem ser caracterizadas como práticas de origens indígenas.

Em que pese a forte permanência histórica (resiliência) do elemento cosmomítico-religioso, o estudo específico das práticas da medicina popular permite evidenciar hibridismos de saberes: aqueles enraizados na cultura indígena (FLORIANI et al, 2016, p.3).

As representações de saúde de comunidades ribeirinhas, que se diferenciam das práticas de cura do meio urbano, possuem a essência baseado no modo de vida e no cotidiano dos moradores do lugar.

Em tal percepção, na concepção cassireriana, a construção do geográfico está diretamente vinculada às várias experiências; o que explica as ações realizadas em momentos específicos, profícuos com relação às temporalidades como fases da lua e aos acontecimentos que são marcantes na vida do coletivo e contribuem na realização dos "marcadores territoriais" (ALMEIDA SILVA, 2015, p.23).

6 Quem mora na várzea.

7 Mesmo que ribeirinho. Quem vive às margens de rio.

Ádria Fabíola Pinheiro de Sousa, Josué Costa da Silva 
O saber local de Dona Lenil com as práticas tradicionais de cura representa muito bem a relação que tem com a cultura indígena, quando da utilização dos "remédios do mato", que são recursos retirados da própria natureza, o que demonstra um modo de vida que respeita, e que por isso mantém uma relação de sobrevivência da natureza para o homem e do homem para a natureza.

Talvez seja essa sintonia com a natureza que, com o aporte da oralidade, mantenha as crenças, os costumes e as tradições dos povos da Amazônia. A sociedade ribeirinha de Aritapera ainda preserva e acredita na funcionalidade dos saberes da medicina tradicional. É por meio dessa crença que Dona Lenil coloca em prática o seu dom de curar que, segundo Nascimento Silva (2004), ao se referir ao dom de carisma, o relaciona a uma divindade. Como costumamos ouvir: "É dom dado por Deus", por que não lhe fora ensinado ou repassado.

Dona Lenil recebeu esse 'dom' e o coloca em prática ajudando os seus "parentes" e vizinhos próximos sem nada cobrar - não que seja proibido mas, para ela é uma forma de retribuir aos outros o dom que ganhara de Deus "é preciso retribuir mais do que se recebeu. A "devolução" é sempre maior e mais cara" (MAUSS, 2003, p.294), e que assim o faz com contentamento. A prática desses saberes culturais são necessários para que possamos entender as dinâmicas sociais do lugar em questão. Compreendemos, então, esses saberes como marcadores culturais do lugar, pois caracterizam e reforçam a sua identidade enquanto moradores ribeirinhos da várzea de Aritapera.

\section{Pensando sobre o Mito}

Antes de abordarmos especificamente sobre as práticas tradicionais de cura, vamos fazer uma breve descrição a respeito do universo mítico, sobre o qual todos os demais acontecimentos estão envoltos.

Para Cassirer, o verdadeiro modelo do mito é a sociedade e todos os seus motivos fundamentais são projeções da vida social. Através destas projeções a natureza torna-se a imagem do mundo social (CASSIRER, 1994). Os temas e motivos do pensamento mítico são imensos, principalmente quando tratado na ótica da medicina convencional e da religião, onde ambos são inacessíveis tanto à religião quanto ao mito ao penetrar nos mistérios da fé, o que transcende a ordem, como as práticas tradicionais de cura, a qual a ciência médica convencional não a reconhece enquanto medicina tradicional ou empírica.

Nessa lógica ocorre o caráter da produção simbólica, em que, para Cassirer a ciência não é idealizada como uma esfera privilegiada do conhecimento, mas que encontra no mesmo nível de objetivação produzida pelos indivíduos, como forma simbólica (ALMEIDA SILVA, 2015, p. 39).

Sendo assim, para Cassirer, não há nenhum fenômeno natural, e nenhum fenômeno da vida humana que não seja passível de uma interpretação mítica e que não peça tal interpretação.

Yu-Fu Tuan também traz a sua contribuição sobre o mito, fazendo a

Ádria Fabíola Pinheiro de Sousa, Josué Costa da Silva 
definição dos espaços míticos.

Podem-se distinguir dois tipos de espaço mítico. Em um deles, o espaço mítico, é uma área imprecisa de conhecimento envolvendo o empiricamente conhecido; emoldura o espaço pragmático. No outro, é o componente espacial de uma visão de mundo, a conceituação de valores, locais por meio dos quais as pessoas realizam suas atividades práticas (TUAN, 2013, p.110).

O que seria essa área imprecisa do conhecimento? Atrelamos a ela as práticas tradicionais de cura que configuram-se como um conhecimento empírico. Podemos também dizer que o espaço das práticas de cura "salva as aparências e explica os acontecimentos", como sugere Tuan (2013, p. 118). É um mito que gira em torno de si mesmo e é na prática que ele se consolida. Consideramos então, ser esta a visão de mundo, relacionado ao mito, para os moradores de Aritapera, pois suas práticas do cotidiano estão atreladas às crenças e modos de cura tradicionais do lugar.

Achamos importante trazer para este artigo a discussão do mito, uma vez que os saberes tradicionais e as práticas tradicionais de cura trazem em sua essência fatos que contradizem os preceitos da ciência, neste caso, da medicina convencional. Assim como o mito, essas práticas trazem consigo manifestações por meio de rituais, orações e crenças que explicam fatos que para a ciência ainda é distante, no tocante aos conhecimentos e saberes populares.

O mito, à primeira vista, parece ser apenas um caos - uma massa disforme de ideias incoerentes. Procurar as "razões" para tais ideias parece fútil e vão. Se existe alguma coisa que seja característico do mito, é o fato de que ele "não tem pé nem cabeça" [...]. No entanto, esses mistérios não contradizem, mas complementam e aperfeiçoam a razão (CASSIRER, 1994, p. 121).

A cultura humana para Cassirer (1994) precede e persegue fins diferentes ao dizer que parece impossível reduzir as criações do mito a um denominador comum.

O mito explica a realidade por meio de suas histórias, ele explica os acontecimentos questionáveis da natureza e das práticas humanas. Acontecimentos podem ser transformados em mito, dependendo da importância simbólica que tem para determinada cultura. Por isso, consideramos o saber de Dona Lenil como crença de caráter mítico, pois as práticas de cura por ela desempenhadas configuram-se em uma simbologia importante para os moradores da Enseada do Aritapera, elas se constituem em medidas resolutivas, proporcionam a saúde e o bem estar dos moradores deste lugar, mesmo que sejam inexplicáveis ou incabíveis mediante aos preceitos da medicina convencional. Para eles são crenças comuns e culturalmente necessárias, por isso, corroboramos ainda com Tuan (2013, p.109) quando diz que "o mito não é uma crença que possa ser facilmente identificada".

Ádria Fabíola Pinheiro de Sousa, Josué Costa da Silva 


\section{As Práticas Tradicionais de Cura}

Identificamos na comunidade Enseada do Aritapera práticas tradicionais de cura que também são conhecidas como medicinas tradicionais, caracterizadas como crença popular que se estabelece a partir da estrutura mítica do lugar relacionada principalmente às benzedeiras.

Para as benzedeiras realizarem os ritos de cura, utilizam plantas medicinais, mas, o uso dessas plantas não são restritas apenas a estas mulheres. $\mathrm{Na}$ verdade, praticamente todos os moradores da comunidade conhecem uma infinidade de ervas medicinais e métodos populares de tratamento de doenças (WAGLEY, 1997). Essas ervas são cultivadas em suas casas, em seus próprios quintais, em hortas suspensas ou no chão e, correspondendo a um sistema de vizinhança, são compartilhas entre si.

As crenças populares da Amazônia constituem em um importante aspecto da concepção geral de um morador rural, simples da região. Tais crenças, aliadas ao procedimento usual a ela associado, frequentemente determinam a aceitação ou a rejeição dos conceitos científicos de importância vital para a transformação técnica do Vale Amazônico (WAGLEY, 1997, p. 215).

A crença nas práticas de curas tradicionais está fortemente atrelada à religião, notadamente à católica e à umbanda por apresentar proximidade em seu método e aplicabilidade, como, por exemplo, por meio da utilização de ervas medicinais, orações, benzeções.

Por outro lado, recebe certa rejeição de religiosos praticantes das religiões pentecostais e neo-pentecostais, o que acaba causando desconforto para quem as praticam. Muitas vezes esses sabedores e/ou "mágicos", como sugere Marcel Mauss, são obrigados a esconderem-se e criarem segredos para si.

Mesmo quando é obrigado a agir diante do público, o mágico busca evadir-se; seu gesto se faz furtivo, sua fala indistinta; o médicofeiticeiro, o curandeiro que trabalha diante da família reunida, murmura entredentes suas fórmulas, dissimula seus passes e envolvese em êxtases fingidos ou reais. Assim, em plena sociedade o mágico se isola, com mais forte razão quando se retira no fundo dos bosques. Mesmo em relação aos colegas, ele mantém quase sempre uma atitude de reserva. O isolamento, como o segredo, é um sinal quase perfeito da natureza íntima do rito mágico. Este é sempre obra de um indivíduo ou de indivíduos que agem de modo privado; o ato e o ator são cercados de mistério (MAUSS, 2003, p. 60).

Nossa colaboradora, Dona Lenil, já teve experiências relacionadas ao preconceito quando foi tachada de "macumbeira" por pessoas de sua própria família, o que revela a presença de preconceito religioso aos que praticam a religião de matriz africana ou a Umbanda, uma vez que, espíritas dessa religião são pejorativamente chamados de "macumbeiros" e têm suas práticas 
religiosas relacionas às atividades que causam mau a alguém, o que é uma inverdade.

No Brasil do século XVI a situação das parteiras, curandeiras e benzedeiras não eram diferentes dos demais países da Europa. Aqui elas não são vistas com bons olhos pela ciência médica e pela inquisição, que também as viam como feiticeiras (NASCIMENTO SILVA, p. 95, 2004).

Os estudos de Eduardo Galvão na década de 1970 no "Vale Amazônico" por ele assim denominado, já apontavam fortes interferências das práticas religiosas na vida dos ribeirinhos do rio Amazonas ocasionadas pela exploração e pela "posse da coroa", impactando negativamente nas práticas religiosas dos indígenas refletidos até os dias atuais, neste mesmo "Vale Amazônico". Para Galvão:

As crenças religiosas que têm origem nas culturas indígenas do vale e são hoje parte do patrimônio caboclo, modificaram-se sob influência do cristianismo e do folclore europeu. Sob nova forma difundiram-se e integraram-se na cultura regional (GALVÃO, 1976, p.115).

Com isso percebemos que novas crenças são inseridas e são responsáveis por uma nova configuração no campo religioso do lugar. Elas entram em cena e vêm acompanhadas pelo preconceito e pela intolerância, sem seus adeptos ou praticantes perceberem que são suas próprias práticas, tradições e histórias que estão sendo apagadas.

Contudo, Dona Lenil não pertence e não demonstra nenhum conhecimento relacionado à religião espírita de matriz africana ou à Umbanda. Por ensinamentos dados por Deus, como ela mesma ressalta, aprendeu a curar e a ajudar ao próximo, o que para Mauss era fundamental para a sobrevivência de todo o grupo social.

A coisa dada produz sua recompensa nesta vida e na outra. Aqui, ela engendra automaticamente para o doador uma coisa idêntica a si mesma: ela não é perdida, ela se reproduz; no outro mundo, é a mesma coisa aumentada que reaparece (MAUSS, 2003, p. 180-181).

Compreendemos a dádiva pensada por Mauss na vida de Dona Lenil pela vontade que ela tem de retribuir aquilo que ganhou, não como uma obrigação, mas como satisfação por ajudar outra pessoa, uma vez que, por meio da teoria da dádiva de Marcel Mouss entendemos que o valor das coisas não pode ser superior ao valor da relação e que o simbolismo é fundamental para a vida social.

As práticas pentecostais e neo-pentecostais estabelecem uma nova sociabilidade que é externa e rompe com as relações locais por não compartilharem da mesma fé. Rompe-se com pessoas, histórias, trajetórias e vidas. 
Ainda hoje, em caso de doenças como vômito, febre, "quebranto", "desmentidura", dor de cabeça, procura-se as benzedeiras, como um serviço alternativo "onde parteiras, curandeiras e benzedeiras assumem um papel preponderante na oferta de atendimentos à saúde" (NASCIMENTO SILVA, 2004, p.73). O vômito e a febre em crianças são sempre correspondentes ao quebranto, que, segundo a crença popular é uma enfermidade ocasionada pelo olhar maldoso de uma pessoa, ou até mesmo por um agrado mal-intencionado. Para que a criança e até mesmo adultos tenham proteção contra esse acometimento, Florêncio Almeida Vaz Filho (2010) orienta que:

Os pais devem por nos filhos recém-nascidos colares e pulseiras com dentes ou ossos de animais ou com algum material colorido, pois geralmente as pessoas olham com admiração para os bebês e podem deixá-los com quebranto, mal-olhado ou qualquer outra enfermidade devido a força do olhar. O colar e a pulseira podem quebrar a força negativa desses olhares. Mesmo pessoas adultas devem usar colares com dentes de animais, sementes ou algo colorido que chame a atenção dos olhos dos outros. O batismo protege a criança desses problemas (VAZ FILHO, 2010, p. 83).

A desmentidura é um termo popular comumente utilizado pelos povos da floresta e até mesmo por moradores da área urbana de cidades da Amazônia, sendo bastante usual na região Norte do país.

Desmentidura ou dismintidura - Junta machucada devido a mal jeito, quedas ou baques; ossos deslocados, destroncados ou batidos. Fala-se que "o osso saíu do lugar" para se referir aos ossos apenas machucados ou mesmo deslocados. Os puxadores é que consertam a dismintidura, o que é uma prática regional. Em outras regiões, onde não há puxadores de dismentidura, os médicos mandam colocar gesso, se for um caso mais sério (VAZ FILHO, 2010, p. 32).

Ainda hoje os ribeirinhos de Aritapera e de outras regiões do Oeste do Pará recorrem a essa prática. $\mathrm{Na}$ área urbana da cidade ainda existem pessoas com este conhecimento, porém, já são poucos e alguns que sabem "puxar" já não o fazem mais devido à força que não têm nas mãos em consequência da idade avançada.

Como vimos, até para a cura de dores de cabeça, os moradores de Aritapera recorrem à Dona Lenil para que ela possa intervir por meio de orações, benzeções e ervas medicinais. O que parece ser uma simples dor de cabeça doença tida como natural - na maioria das vezes está atrelada às doenças de mau-olhado de pessoas e de bichos (também conhecido como flechada de bicho) ocasionada por seres encantados das águas e da mata, por isso, a pessoa que sofre com esse tipo de dor de cabeça necessita de cuidados especiais que podem ser encontrados nas mãos de uma benzedeira.

Para todas essas doenças citadas acima e para tantas outras, a benzeção está sempre presente, talvez por ser uma saída mais imediata que os ribeirinhos

Ádria Fabíola Pinheiro de Sousa, Josué Costa da Silva 
encontram para solucionarem suas doenças.

Benzedor - Homem ou mulher que cura as pessoas através de rezas ou bênçãos, geralmente usando um ramo de alguma planta sobre a cabeça do enfermo durante a oração. Acredita-se que benzedores curam doenças mais simples, como quebranto em crianças, mauolhado ou assombrado. Os casos mais sérios, como ataques de bichos encantados ou gente que fica doida, são mandados aos pajés. Às vezes o mesmo benzedor é puxador de dismentiduras nos ossos (VAZ FILHO, 2010, p.18).

Como percebemos na citação acima, tanto mulheres quanto homens podem ser benzedores, contudo, $\mathrm{o}$ ato de benzer parece ser mais comum às mulheres, ficando para os homens a função de pajé. É mais comum de se ver homens pajés que mulheres pajés.

Essas práticas se atrelam ao conhecimento de cura por meio de práticas tradicionais e à religião, principalmente à católica e à Umbanda. À primeira pela utilização das orações como o Pai-Nosso, Ave-Maria, Santa-Maria, Salve Rainha, Credo; e à última pela utilização das ervas medicinais utilizadas para a feitura de chás e banhos.

Percebemos na comunidade Enseda do Aritapera essa essência realidade presentificada e manifestada através das práticas tradicionais de cura. Essa manifestação do saber tradicional, além de auxiliar no tratamento de doenças, sejam elas naturais ou não naturais, reafirma a cultura das pessoas que acreditam na funcionalidade dessas práticas e desses saberes.

Dona Lenil atribui alguns de seus conhecimentos a revelações dadas por Deus, na hora que alguém recorre a ela, dependendo da necessidade, Deus lhe revela o que ela tem de fazer, mas também é importante que a pessoa tenha fé em sua prática "eu digo, vai da fé! Se a pessoa tem fé ela é curada, senão, ela não é!" (Lenil Silva, Enseada do Aritapera, 12.10.2015). Segundo Dona Lenil, Deus é o responsável pelo sucesso de suas curas.

Eu acho que a força da oração, ela sempre... como a gente viu naquele dia a leitura... "tudo o que pedires em meu nome, Deus te dá!’ Eu acho que, quando a pessoa vem aqui... olha, o filho da Sofia pegou uma sangue suga na perna dele. Ele trouxe aqui, mas enorme a perna, tudo vermelho... Dona Lenil, benza pro meu filho. Ai eu fiquei olhando. Eu sabia que era um ato daquele e rezei! E olha, quando ela chegou lá ela furou e vazou que esvaziou aquilo tudinho. Diz ela que ele tava bem melhor. Deus viu que ele tava sofrendo e pediu. Tipo mesmo uma benzeção. Aí eu peguei e fui. Aí, eu fui três dias fazer pra ele lá. Pois olha, tu sabes que ele ficou bonzinho. Ai ele mandou me chamar... Eu disse: Deus foi que fez essa obra pra ti, não foi eu, foi Ele. Ele que permitiu! (Lenil Silva, Enseada do Aritapera, 12.10.2015).

Consideramos então que essas práticas acontecem em um plano real, pois sua ação é resolutiva por atender às necessidades de pessoas que recorrem a

Ádria Fabíola Pinheiro de Sousa, Josué Costa da Silva 
esta sabedora senhora. Como ela mesma relata:

[...] e tudo é assim, por acaso dá certo, a criança fica boa e... mas não de dizer assim, que eu tenho um poder, mas eu fico satisfeita por poder ajudar, porque, aonde não tem tanto recurso né?! (Lenil Silva, Enseada do Aritapera, 12.10.2015).

Para tratarmos especificamente sobre as práticas tradicionais de cura, utilizaremos como aporte teórico a obra "A ilha encantada" de Maués (1990) que traz uma abordagem sobre as práticas de cura naturais e não naturais.

As práticas de cura naturais são as relacionadas com as medidas convencionais da medicina, já as não naturais estão atreladas a acontecimentos "sobrenaturais" ou a energias místicas.

[...] As doenças naturais são consideradas como tendo causas de ordem natural ou normal, as causas das doenças não-naturais são consideradas pelos itapuaenses como anormais. Por isso eles afirmam que o tratamento das doenças não-naturais não pode ser feito pela "medicina" (isto é, a medicina ocidental), pois o médico e outros especialistas que seguem a sua orientação, não compreendem esse tipo de doença, do que resulta a ineficácia do tratamento feito por eles (MAUÉS, 1990, p. 41).

As pessoas que tratam dessas doenças, segundo Eraldo Maués, são chamadas de especialistas e, dependendo da doença e de sua causa, esses especialistas são divididos em duas categorias: experientes 1 e experientes 2 .

O experiente é consultado, sobretudo para as doenças naturais. Seus métodos de tratamento incluem o uso de chás, "leite de paus" (isto é, seiva de diversas plantas), emplastros, banhos, defumações, pomadas, fricções, vomitórios, excremento de animais, saliva humana e outros. Seus remédios constituem tanto o que chamam de "remédios da terra" (ou do "mato"), que são conservados pela tradição local, passando de geração a geração, como os "remédios de farmácia" (injeções, comprimidos, pomadas, xaropes, etc) [...] (MAUÉS, 1990, p.204205).

Caracterizamos as práticas de Dona Lenil como uma experiente/especialista no tratamento de doenças naturais, uma vez que ela exerce práticas de cura como as citadas abaixo:

Tinha uma menina ali pra baixo que por nada o ombro dela deslocava, arriava o braço dela, fica muito feio isso descolocado (ela é até minha afilhada). Ela vinha aqui, "minha madrinha, olha o meu braço”. Ai eu pelejava, porque tem que meter a mão aqui (mostra o local) e daí carregava pra colocar no lugar. Mas eu vou fazer um remédio pra ti. Aí eu peguei o emplasto e ungi, coloquei e disse:

Ádria Fabíola Pinheiro de Sousa, Josué Costa da Silva 
nunca mais o teu braço vai cair. E tu sabes que ela ficou boa? Nunca mais o braço dela caiu! E é assim, eu via muitas velhas fazerem esse remédio (Lenil Silva, Enseada do Aritapera, 12.10.2015).

Bem como, Dona Lenil pode ser denominada como uma experiente/especialista de doenças não naturais, uma vez que ela exerce a prática de benzedeira.

O benzedor é um especialista que, muitas vezes, agindo como simples experiente, é capaz de tratar de várias doenças naturais [...], mas ele se distingue do experiente pelo fato de saber benzer seus pacientes recitando orações próprias e assumindo um comportamento ritual específico. A "benzição" é a forma de tratamento mais importante para algumas doenças naturais (cobrelo, erzipla, fogo selvage, etc.) e não naturais (quebranto e todas as formas de mau-olhado) (MAUÉS, 1990, p.212).

Dona Lenil age na cura de quebranto, mau-olhado, dentre outras doenças que são consideradas naturais, mas que, para as quais, nossa sabedora se utiliza de benzeções e orações.

Eu rezo sim, agora espinha é assim, porque diz assim ${ }^{8} \ldots$ O marido da Arlete veio aqui à boca da noite, ele ainda foi com a espinha, quando foi no outro dia, era umas sete horas, que a filha da Arlete telefonou. Eu disse: O que tu queres? O teu pai tá passando mal? - Não, eu to ligando pra lhe avisar, pra senhora agradecer pro seu santinho, que ele botou a espinha (Lenil Silva, Enseada do Aritapera, 12.10.2015).

Diante das práticas de cura exercidas por Dona Lenil, percebemos a sua importância na comunidade e a importância de suas ações enquanto sabedora.

O homem precisa tanto de tais fontes simbólicas de iluminação para encontrar seus apoios no mundo porque a qualidade não-simbólica constitucionalmente gravada em seu corpo lança uma luz muito difusa (GEERTZ, 1988, p.33).

A simbologia desse saber está para além de sua aplicabilidade e efetividade quanto a resolução de um problema - doença - elas representam a perpetuação de uma crença de um determinado grupo social - ribeirinhos - em sua própria realidade.

$\mathrm{Na}$ fronteira entre mundo material, onde se insere a atividade humana, e o mundo imaginário, abrindo seu conteúdo simbólico à liberdade do espírito, nós reencontramos aqui uma geografia interior, primitiva, em que a espacialidade original e a mobilidade profunda do homem

8 Preferimos preservar a oração relatada por Dona Lenil, considerando que as sabedoras e sabedores só repassam os seus conhecimentos às pessoas de confiança ou que tenham alguma aproximação com as práticas de cura.

Ádria Fabíola Pinheiro de Sousa, Josué Costa da Silva 
designam as direções, traçam os caminhos para um outro mundo; a leveza se liberta dos pensadores para se elevar aos cumes. A geografia não implica somente no reconhecimento da realidade em sua materialidade, ela se conquista como técnica de irrealização, sobre a própria realidade (DARDEL, 2011, p.5).

Consideramos, portanto, a possibilidade que a Geografia nos oferece para estudar e dar visibilidade aos saberes de pessoas que curam por meio de saberes e práticas tradicionais que é uma construção coletiva pertencente à cultura dos moradores de Aritapera, levando em consideração que "a cultura nada mais é do que uma expressão das formas simbólicas que permeiam as mais diversas coletividades" (ALMEIDA SILVA, 2015, p.22).

Ela nos permite investigar a realidade intrínseca dos povos da Amazônia, envoltas de mistérios e encantamentos, mais que isso, a geografia nos desafia a ter responsabilidade e compromisso junto a essas populações, no intento de ajudá-los a preservar esses saberes que intensificam sua identidade de ribeirinhos.

\section{Considerações}

Os saberes e as práticas tradicionais de cura na comunidade Enseada do Aritapera configuram a identidade dos moradores desse lugar que acreditam e recorrem a eles. Dona Lenil é uma pessoa fundamental na aplicabilidade desses saberes, uma vez que ela é uma das poucas que desempenham esse papel de sabedora/curadora ou, como configura Maués experiente/especialista do lugar, sendo conhecida, principalmente, como benzedora e puxadora da comunidade, a quem os comunitários costumam dizer: "ela sabe, ela entende, ela conhece". A partir disso, percebemos a projeção da vida social desta comunidade, no que diz respeito às práticas tradicionais de cura, por isso a importância de entender o processo mítico nessa configuração simbólica, uma vez que o modelo do mito é a sociedade.

Contudo, percebemos que na comunidade Enseada do Aritapera há uma limitação da transmissão dos saberes e práticas tradicionais de cura, por meio da oralidade. Dona Lenil não tem filhos, mas tem sobrinhas e sobrinhos para quem poderia transmitir esse conhecimento, mas não o faz porque estes seus familiares não têm interesse em aprender.

Além disso, o acesso às práticas urbanas também acabam intervindo nas práticas tradicionais de cura nesse lugar, uma vez que; quando acessadas, acabam substituindo as práticas tradicionais por aquelas. Com isso, podemos pensar então em uma desvalorização da prática tradicional de cura. Nesse sentido, os estudos acadêmicos podem colaborar com esses sujeitos, promovendo o conhecimento/reconhecimento e a valorização desses saberes, das sabedoras e sabedores.

Essas práticas tradicionais de cura atendem a uma demanda no tratamento de doenças na comunidade Enseada do Aritapera, elas acabam sendo resolutivas e por isso são incorporadas ao cotidiano dessa comunidade. A partir disso, vê-se a necessidade de salvaguardar esse conhecimento tradicional, por meio da história oral ou por meio de documentários audiovisuais que poderiam

Ádria Fabíola Pinheiro de Sousa, Josué Costa da Silva 
ser disponibilizados em espaço/centro/lugares de memórias.

As práticas tradicionais de cura - elementos míticos que, com muita excelência envolvem a vida de Dona Lenil e dos moradores da comunidade Enseada do Aritapera - é um essencial marcador e definidor de sua identidade e que, juntamente a outros elementos - dão o sentido de pertencimento ao lugar e configuram um grupo social formado intrinsecamente por ribeirinhas e ribeirinhos. Mas, vale dizer que essa identidade, apesar de estarmos tratando de uma comunidade ribeirinha, não necessariamente é idêntica às outras comunidades das beiras de rio. O Aritapera, dentre um universo mais amplo, ganha suas especificidades.

\section{Referências}

ALMEIDA SILVA, Adnilson de. Territorialidades e Identidade dos Coletivos Kawahib da Terra Indígena Uru-Eu-Wau-Wau em Rondônia: "Orevaki Are" (reencontro) dos "marcadores territoriais". Jundiaí: Paco Editorial, 2015.

CASSIRER, Ernest. Ensaio sobre o homem: Introdução a uma filosofia da cultura humana. São Paulo: Martins Fontes, 1994.

DARDEL, Eric. O Homem e a terra: Natureza da realidade geográfica. São Paulo: Perspectiva, 2011.

FLORIANI, Nicolas et all. Medicina popular, catolicismo rústico, agrobiodiversidade: $\mathrm{O}$ amálgama cosmo-mítico-religioso das territorialidades tradicionais na região da serra das almas, Paraná, Brasil. Geografia, v. 41, n. 2, p. $331-350,2016$.

GALVÃO, Eduardo. Santos e visagens: Um estudo da vida religiosa de Itá. $2^{\text {a }}$ ed, Brasília: Nacional, 1976.

GEERTZ, Clifford. A interpretação das culturas. Rio de Janeiro: Zahar, 1988.

LOUREIRO, João de Jesus Paes. Cultura Amazônica: Uma poética do imaginário. Belém: Cejup, 1995.

MAUÉS, Heraldo. A ilha encantada: Medicina e xamanismo numa comunidade de pescadores. Belém: UFPA, 1990.

MAUSS, Marcel. Sociologia e antropologia. São Paulo: Cosacnaify, 2003.

NASCIMENTO SILVA, Maria das Graças Silva. Parteiras Ribeirinhas: Saúde da mulher e o saber local. 2004. Tese (Doutorado em Desenvolvimento Sustentável do Trópico Úmido) - Universidade Federal do Pará, Belém, Pará.

NASCIMENTO SILVA, Maria das Graças Silva. O espaço ribeirinho. São Ádria Fabíola Pinheiro de Sousa, Josué Costa da Silva 
Práticas de Cura pelas Mãos de Dona Lenil, Sabedora da Comunidade

Enseada do Aritapera, Várzea de Santarém, Pará

Paulo: Terceira Margem, 2000.

TUAN, Yu-Fu. Espaço e lugar. A perspectiva da experiência. Londrina: Eduel, 2013.

VAZ FILHO, Florêncio Almeida. Dicionário Papa-Xibé do Baixo Amazonas. Santarém: Radio Rural de Santarém, 2010.

WAGLEY, Charles. Uma comunidade amazônica: Estudo dos homens nos trópicos. São Paulo: Nacional, 1997. 